\title{
HIỆU QUẢ VÀ TÁC DỤNG KHÔNG MONG MUỐN CỦA DƯNG CỤ ANCHORFAST TRONG CỐ ĐINH ỐNG Nô̂I KHÍ QUẢN Ở CÁC BỆNH NHẦN THỞ MÁY
}

\section{TÓM TẮT}

Nghiên cứu nhằm so sánh hiệu quả cố định ống NKQ bằng dụng cụ AnchorFast và băng dính ở các bệnh nhân thở máy. Đây là nghiên cứu can thiệp ngẫu nhiên có nhóm chứng. Kết quả nghiên cứu cho thấy trong 60 bệnh nhân được chia thành 2 nhóm ngẫu nhiên, không có bệnh nhân nào được cố định ống NKQ bằng dưng cụ ÁnchorFast bi di lệch hoặc tuột ống ngoài ý muốn. Trong khi đó tỷ lệ bị di lệch ống NKQ ở nhóm cố định bằng băng dính chiếm là $7 / 30(23,3 \%)$ và có $1 / 30(3,3 \%)$ bệnh nhân bị tuột ống ngoài ý muốn. Tỉ lệ loét liên quan đến cố định bằng băng dính là 10/30 (33,3\%), cố định bằng dụng cụ AnchorFast là $4 / 30(13,3) \%$. Trong đó, vị trí loét trong AnchorFast gặp ơ 2 vị trí là lưỡi: $3 / 30(10 \%)$ và môi: $1 / 30$ $(3,33 \%)$, chủ yếu ở giai đoan I: $3 / 30(10 \%)$ và giai đoan II: $1 / 30$ (3,33\%). Ơ nhóm dùng băng dính, vị trí loét tại 2 vị trí lưỡi: $4 / 30(13,33 \%)$ và môi: $6 / 30$ $(20 \%)$, giai đoan loét I: $7 / 30(23,33 \%)$, giai đoan II: $3 / 30(10 \%)$. Nghiên cứu cho thấy hiệu quả cố định ống NKQ ở nhóm bệnh nhân sử dụng AnchorFast cao hơn nhóm sử dụng băng dính về độ di lệch ống và tuột ống ngoài ý muốn. Tý lệ bị loét ở nhóm sử dụng AnchorFast thấp hơn nhóm cố định bằng băng dính.

Tư khoá: AnchorFast, cố định ống nội khí quản, băng dính, bệnh nhân thở máy xâm nhập

\section{SUMMARY \\ EFFECTS AND ADVERSE EFFECTS OF THE ANCHORFAST DEVICE IN SECURING THE ENDOTRACHEAL TUBE IN INVASIVE \\ MECHANICALLY VENTILATED PATIENTS}

The study aimed to compare the effectiveness of the endotracheal tube securement by AnchorFast and by adhesive tape in Invasive mechanically ventilated patients. This was a randomised control intervention study, the study showed that in 60 patients divided into 2 groups, none of the patients who had with the AnchorFast device had an unintended deviation or endotracheal tube slip. Meanwhile, in the adhesive tape group the rate of endotracheal tube deviation was $7 / 30(23.3 \%)$ and of unintended extubation was $1 / 30(3.3 \%)$. The rate of ulcer in the adhesive tape of $10 / 30(33.3 \%)$, in the AnchorFast of $4 / 30$ (13.3\%). In particular, the ulcer point in AnchorFast was found in tongue of $3 / 30(10 \%)$ and lips of $1 / 30(3.33 \%)$,

\footnotetext{
${ }^{1}$ Bệnh viện Đại học Y Hà Nội

2Trường đai hoc Y Hà Nôi

Chịu trách nhiệm chính: Hoàng Bùi Hải

Email: hoangbuihai@hmu.edu.vn

Ngày nhân bài: 8.9.2021

Ngày phản biên khoa họ: 27.10.2021

Ngày duyệt bài: 9.11.2021
}

\section{Đàm Thị Hương Lan ${ }^{1}$, Hoàng Bùi Hải ${ }^{1,2}$}

mainly in stage I of $3 / 30(10 \%)$ and stage II of $1 / 30$ $(3.33 \%)$. In the adhesive tape group, the ulcer was located on tongue of $4 / 30(13,33 \%)$ and lips of $6 / 30$ $(20 \%)$, at stage I of $7 / 30(23.33 \%)$, at stage II of $3 / 30(10 \%)$. The study showed that the effectiveness of intubation securement by AnchorFast device was higher than that of the group using adhesive tape in terms of unintended tube deviation and endotracheal tube slip. The ulcer rate of the group of AnchorFast was lower than group of adhesive tape tube fixation.

Keywords: AnchorFast device, endotracheal intubation tube securement, adhesive tape, invasive mechanically ventilated patients

\section{I. ĐẶT VẤN ĐỀ}

Đă̆t ống nôi khí quản (NKQ) là phương pháp không thể thiếu được sử dung trong gây mê, phẫu thuật, hồi sức và cấp cứu. Theo nghiên cứu của Hampson (2018) tại một đơn vị Hồi sức tích cực (ICU) ở Úc có khoảng $40 \%$ bềnh nhân thở máy xâm lấn mỗi năm. ${ }^{1}$ Cố định ống NKQ là môt thực hành hàng ngày quan trọng và phổ biến đối với điều dương ở đơn vi cấp cứu \& hồi sức tích cực (CC\&HSTC). ${ }^{2}$ Có rất nhiêu phương pháp được sử dụng để cố định ống NKQ như dây buộc, băng dính hoặc các dụng cụ cố định thương mại khác mà gần đây ở Việt Nam mới được đưa vào áp dụng là AnchorFast. Phương pháp cố định ống NKQ hiệu quả nhất là phương pháp giúp ống NKQ ít bị di chuyển sai lệch vị trí nhất, cung cấp khả năng chống lai dich tiết miêng mà không bi lỏng lẻo, thao tác cố định dễ dàng và mất ít thời gian, đồng thời cũng phải thuân tiện trong chăm sóc răng miêng và hạn chế chấn thương áp lực cho bệnh nhân.

Có rất nhiêu nghiên cứu được thực hiên để đánh giá sư hiệu quả của các phương pháp cô định ống nội khí quản, tuy nhiên chưa có nghiên cứu nào chứng minh được tính ưu việt của một phương pháp cố định cụ thể. Ở Việt Nam, các bài nghiên cứu hay bài báo cáo về so sánh hiệu quả của các loại cố đinh ống nôi khí quản còn rất han chế. Trên thế giới, các nghiên cứu đánh giá hiệu quả sử dụng của AnchorFast cho những kết quả trái chiều, không đồng nhất. Gardner và các công sự đã thực hiện một thử nghiệm ngẫu nhiên có đối chứng so sánh hiệu quả của sáu phương pháp cố định ống NKQ. Kết quả chỉ ra rằng không có phương pháp cố định ống NKQ nào có thể được xác định là ưu việt để giảm 
thiểu sự dịch chuyển ống, tụt ống và rút ống ngoài ý muốn. ${ }^{3}$ Một nghiên cứu của Janna $S$. Landsperger nhận thấy rằng việc sử dụng AnchorFast cố định ống NKQ làm giảm đồng thời tỉ lệ loét môi, rách da măt và tuột ống NKQ so với băng dính, thời gian nẳm viện và tỉ lệ tử vong không có sự khác biệt giữa hai nhóm. ${ }^{4}$ Một nghiên cứu khác của Żaratkiewicz (2012) cũng cho kết quả tương tự, tỷ lệ loét miệng sau khi sử dụng AnchorFast giảm 6 lần so với băng dính, từ $1,25 \%$ xuống còn $0,2 \% .^{5}$ Trong khi đó, nghiên cứu của Hampson (2018), đánh giá về tác động của thiết bị AnchorFast đối với tỷ lệ loét miệng cho thấy tỷ lệ loét áp lực tăng đáng kể sau khi sử dụng AnchorFast, có sự khác biệt về vị trí loét giữa hai phương pháp cố định. ${ }^{2}$

Từ năm 2019, khoa CC \& HSTC bệnh viện Đại học Y Hà Nội đã bắt đầu thực hiện sử dụng cố định ống NKQ chống cắn AnchorFast cho các bệnh nhân thở máy, tuy nhiên vẫn chưa có nghiên cứu nào về vấn đề này. Vì vậy, chúng tôi tiến hành nghiên cứu: "Hiệu quả và tác dụng không mong muốn của dụng cụ AnchorFast trong cố định ống nội khí quản ở các bệnh nhân thở máy" nhằm mục tiêu: "So sánh hiệu quả cố định ống NKQ của hai phương pháp sử dụng dụng cụ AnchorFast và sư dụng băng dính ở các bệnh nhân thở máy tại khoa Cấp cứu \& hồi sức tích cực bệnh viện Đại học Y Hà Nội"

\section{II. ĐỐI TƯợNG VÀ PHƯƠNG PHÁP NGHIÊN CỨU \\ 2.1. Đối tượng nghiên cứu}

- Tiêu chuấn lựa chơn: Bệnh nhân được đặt ống nội khí quản tại khoa CC \& HSTC bệnh viện Đại học Y Hà Nội, tuổi $\geq 18$ tuổi và thời gian lưu ống nội khí quản $\geq 24$ giờ.

- Tiêu chuân loại trừ:

- Bệnh nhân không có răng hoặc răng bị nhô ra ngoài.

- Bệnh nhân bị chấn thương miệng, chấn thương hàm mặt trước khi đặt ống nội khí quản.

- Bệnh nhân bị phù mặt.

- Bệnh nhân bị viêm, loét, nhiễm trùng vùng da mặt, môi, và trong khoang miệng trước khi đặt ống NKQ.

- Bệnh nhân hoặc gia đình không đồng ý tham gia nghiên cứu.

- Địa điểm: Khoa Cấp cứu và Hồi sức tích cực bệnh viện Đại học Y Hà Nội

- Thời gian: Từ tháng 06/2020 đến tháng 05/2021

\subsection{Phương pháp nghiên cứu}

2.2.1. Thiết kế nghiên cứu: nghiên cứu can thiệp có nhóm chứng

2.2.2. Công cụ thu thập số liệu. Dữ liệu được thu thập bằng cách sử dụng một công cụ dựa trên thang tổn thương áp lực của Hội đồng tư vấn chấn thương áp lực Anh quốc (NPUAP), việc phân loại các vết loét được chia thành 4 giai đoạn bao gồm: Giai đoạn I: Vùng da bị đè ép nổi lên vết rộp màu hồng; Giai đoạn II: Mất một phần biểu bì, biểu hiện là loét hở nông với đáy vết loét màu đỏ hồng, không đóng vảy; Giai đoạn III: Mất mô toàn bộ lớp da, có thể thấy mô mớ dưới da nhưng không lộ xương, gân hay cơ; Giai đoạn IV: Hoại tử toàn bộ lớp da, có khi lan rộng đến cả vùng cơ, xương, khớp, đôi khi tạo nhiều ngóc ngách. ${ }^{6}$

Công cụ thu thập dữ liệu cũng được sử dụng theo Hướng dẫn đánh giá miệng (OAG) từ hướng dẫn thực hành lâm sàng điều dưỡng của Bộ $Y$ tế 1/2004 trên bệnh nhân được xác định là cần hỗ trợ vệ sinh răng miệng trong quá trình đánh giá thường quy. Bảng cầu hỏi bao gồm 8 mục, trong đó chọn ra 6 mục phù hợp với nghiên cứu. Mối mục được đánh giá theo 3 cấp độ: 1 = Kết quả bình thường; 2 = Bất thường nhẹ mà không ảnh hưởng đến tính toàn vẹn của niêm mạc hoặc mất chức năng; 3 = Bất thường nghiêm trọng, mất tính toàn vẹn niêm mạc hoặc mất chức năng.

2.2.3. Phương pháp phân tích số liệu. Số liệu được xử lí bằng phần mềm IBM SPSS 22.0.

2.3. Đạo đức nghiên cứu. Nghiên cứu được thực hiện dưới sự đồng ý của người nhà bệnh nhân. Số liệu thu thập được chỉ phục vụ mục đích nghiên cứu, không sử dụng vào mục đích nào khác.

\section{KẾT QUẢ NGHIÊN CỨU}

3.1 Đặc điểm của đối tượng nghiên cứu

Bảng 3.1. Đặc điểm của đối tượng nghiên cứu

\begin{tabular}{|c|c|c|c|c|c|c|c|c|c|c|c|c|c|}
\hline \multirow{3}{*}{\multicolumn{2}{|c|}{ Phương pháp }} & \multirow{3}{*}{$\begin{array}{l}\text { Tuổi } \\
\text { trung } \\
\text { bình } \\
\text { (tuổi) }\end{array}$} & \multicolumn{4}{|c|}{ Giới } & \multirow{3}{*}{$\begin{array}{l}\text { BMI } \\
(\underset{2}{\mathrm{~kg} / \mathrm{m}})\end{array}$} & \multirow{2}{*}{\multicolumn{2}{|c|}{$\begin{array}{l}\text { Bệnh lý } \\
\text { mạch máu } \\
\text { ngoại biên }\end{array}$}} & \multirow{2}{*}{\multicolumn{2}{|c|}{$\begin{array}{l}\text { Đái tháo } \\
\text { đường }\end{array}$}} & \multirow{2}{*}{\multicolumn{2}{|c|}{$\begin{array}{c}\text { Dùng } \\
\text { steroid kéo } \\
\text { dài }\end{array}$}} \\
\hline & & & \multicolumn{2}{|c|}{ Nam } & \multicolumn{2}{|r|}{ Nữ } & & & & & & & \\
\hline & & & $\mathbf{n}$ & $\%$ & $\mathbf{n}$ & $\%$ & & Có & Không & Có & Không & Có & Không \\
\hline $\begin{array}{c}\text { AnchorFa } \\
\text { st }\end{array}$ & $n=30$ & $\begin{array}{l}66,5 \pm \\
18,86\end{array}$ & 14 & 46,67 & 16 & 53,33 & $\begin{array}{l}22,39 \\
\pm 4,33\end{array}$ & 2 & 28 & 7 & ming & 1 & 29 \\
\hline Băng & $n=30$ & $63,3 \pm$ & 22 & 73,33 & 8 & 26,67 & 20,42 & 1 & 29 & 9 & 21 & 0 & 30 \\
\hline
\end{tabular}




\begin{tabular}{|c|c|c|c|c|c|c|c|c|c|c|c|c|c|}
\hline dính & & 17,55 & & & & & $\pm 3,09$ & & & & & & \\
\hline \multicolumn{2}{|c|}{$\mathrm{p}$} & 0,5 & & & & & 0,047 & & & & & & \\
\hline Tổng & $\mathrm{n}=60$ & $\begin{array}{l}64,9 \pm \\
18,13\end{array}$ & 36 & 60 & 24 & 40 & $\begin{array}{l}21,40 \\
\pm 3,86\end{array}$ & 3 & 57 & 16 & 44 & 1 & 59 \\
\hline
\end{tabular}

Nhận xét: Độ tuối trung bình của 60 bệnh nhân tham gia nghiên cứu là 64,9 tuổi $( \pm 18,13)$ với chỉ số BMI trung bình là $21,40( \pm 3,86)$. Tỷ lệ bệnh nhân nam tham gia nghiên cứu là $60 \%$, bệnh nhân nữ là $40 \%$, trong đó tỷ lệ bệnh nhân nam, nữ ở nhóm AnchorFast khá tương đương nhau lần lượt là $46,67 \%$ và $53,33 \%$. Trong 30 bênh nhân ở nhóm sử dụng băng dính, tỷ lệ nam giới gấp gần 3 lần nữ giới lần lượt là $73,33 \%$ và $26,67 \%$.

Số bênh nhân có bênh nền về bênh đái tháo đường là cao nhất (16/60 bệnh nhân), trong đó có 7 bệnh nhân ở nhóm AnchorFast, 9 bệnh nhân ở nhóm băng dính. Nhóm mắc bệnh lý mạch máu ngoại biên đứng thứ 2 (3/60 bệnh nhân), nhóm dùng steroid kéo dài chỉ có 1 bệnh nhân thuộc nhóm AnchorFast.

3.2. Hiệu quả của hai phương pháp cố định ống nội khí quản ở các bệnh nhân thở máy

Bảng 3.2. Hiệu quả trong cố định ống nội khí quản

\begin{tabular}{|c|c|c|c|c|c|c|c|c|c|c|}
\hline \multirow{3}{*}{ Phương pháp } & \multirow{3}{*}{$\begin{array}{c}\text { Số ngày lưu } \\
\text { ống NKQ } \\
\text { trung bình } \\
\text { (ngày) }\end{array}$} & \multirow{3}{*}{$\begin{array}{c}\text { Số lân thay } \\
\text { đổi } \\
\text { vị trí ống NKQ } \\
\text { (lần/ngày) }\end{array}$} & \multirow{2}{*}{\multicolumn{2}{|c|}{$\begin{array}{c}\text { Số BN bị } \\
\text { di lệch } \\
\text { ống NKQ }\end{array}$}} & \multirow{2}{*}{\multicolumn{2}{|c|}{$\begin{array}{c}\text { Độ di } \\
\text { lệch ống } \\
\text { NKQ min }\end{array}$}} & \multirow{2}{*}{\multicolumn{2}{|c|}{$\begin{array}{l}\text { Đô di } \\
\text { lệ̂ch } \\
\text { ổng } \\
\text { NKQ } \\
\text { max }\end{array}$}} & \multirow{3}{*}{\begin{tabular}{|c|} 
Đố di \\
lệch \\
ống NKQ \\
trung \\
bình \\
(cm) \\
cm
\end{tabular}} & \multirow{3}{*}{$\begin{array}{c}\text { Tuột } \\
\text { ống } \\
\text { NKQQ } \\
\text { ngoài } \\
\text { ý } \\
\text { muốn } \\
\text { n }\end{array}$} \\
\hline & & & & & & & & & & \\
\hline & & & $\mathbf{n}$ & $\%$ & $\mathbf{c m}$ & $\mathbf{n}$ & $\mathbf{c m}$ & $\mathbf{n}$ & & \\
\hline AnchorFast $n=30$ & & & 0 & 0 & 0 & 0 & 0 & 0 & 0 & 0 \\
\hline Băng dính $n=30$ & $6,50 \pm$ & $1,00 \pm 0,00$ & 7 & 23,33 & 1 & 6 & 2 & 1 & 1,14 & 1 \\
\hline & 0,26 & 0,00 & & & & & & & & \\
\hline
\end{tabular}

Nhân xét: Số ngày lưu ống NKQ trung bình ở cả 2 nhóm là 6 ngày, trong đó số lần thay đổi vị trí ống nội khí quản trong 1 ngày ở nhóm AnchorFast cao gấp 7 lần so với nhóm băng dính. Không ghi nhận bệnh nhân nào bị di lệch ống NKQ và tuột ống ở nhóm sử dụng AnchorFast. Với nhóm băng dính, tỷ lệ di lệch ống là $23,33 \%$ và có 1 bệnh nhân bị tuột ống NKQ

Bảng 3.3. Hiệu quả trong chăm sóc răng miệng

\begin{tabular}{|c|c|c|c|c|c|c|c|c|}
\hline & \multirow{2}{*}{$\begin{array}{l}\text { Thời gian chăm } \\
\text { sóc răng miệng } \\
\text { trung bình } \\
\text { (phút/liân) }\end{array}$} & \multicolumn{6}{|c|}{ Điếm OAG trung bình } \\
\hline & & & Môi & Lưỡi & $\begin{array}{c}\text { Nước } \\
\text { bọt }\end{array}$ & Nướu & $\begin{array}{c}\text { Niêm } \\
\text { mạc } \\
\text { miệng }\end{array}$ & Răng \\
\hline AnchorFast & $n=30$ & $6,09 \pm 0,80$ & $\begin{array}{c}1,53 \pm \\
0,68 \\
\end{array}$ & $\begin{array}{c}1,57 \pm \\
0,68\end{array}$ & $\begin{array}{c}1,70 \pm \\
0,53\end{array}$ & $\begin{array}{c}1,17 \pm \\
0,38\end{array}$ & $\begin{array}{c}1,17 \pm \\
0,38\end{array}$ & $\begin{array}{c}1,33 \pm \\
0,55\end{array}$ \\
\hline Băng dính & $n=30$ & $9,48 \pm 1,27$ & $\begin{array}{c}1,83 \pm \\
0,46\end{array}$ & $\begin{array}{c}1,77 \pm \\
0,57\end{array}$ & $\begin{array}{c}1,57 \pm \\
0,50\end{array}$ & $\begin{array}{c}1,20 \pm \\
0,40\end{array}$ & $\begin{array}{c}1,33 \pm \\
0,48\end{array}$ & $\begin{array}{c}1,47 \pm \\
0,57\end{array}$ \\
\hline $\mathbf{p}$ & & 0,0 & 0,051 & 0,221 & & 0,744 & 0,141 & 0,360 \\
\hline Tổng & $n=60$ & $7,79 \pm 2,01$ & $\begin{array}{c}1,68 \pm \\
0,60\end{array}$ & $\begin{array}{c}1,67 \pm \\
0,63\end{array}$ & $\begin{array}{c}1,63 \pm \\
0,52\end{array}$ & $\begin{array}{c}1,18 \pm \\
0,39\end{array}$ & $\begin{array}{c}1,25 \pm \\
0,44\end{array}$ & $\begin{array}{c}1,40 \pm \\
0,56\end{array}$ \\
\hline
\end{tabular}

Nhận xét: Thời gian chăm sóc răng miệng trung bình ở nhóm băng dính là 9 phút dài gấp 1,5 lần thời gian chăm sóc răng miệng trung bình ở nhóm AnchorFast (6 phút), sự khác biệt có ý nghĩa thống kê với khoảng tin cậy $95 \%(\mathrm{p}<0,05)$. Điểm OAG tại 6 vị trí đánh giá khác biệt không có ý nghĩa thống kê với khoảng tin cây $95 \%(p>0,05)$

3.3. Tác dụng không mong muốn của hai phương pháp cố định ống nội khí quản ở các bệnh nhân thở máy

Bảng 3.4. Đặc điểm loét liên quan đên hai phương pháp cố định ống NKQ

\begin{tabular}{|c|c|c|c|c|c|c|c|c|c|}
\hline \multirow[b]{3}{*}{ Phương pháp } & \multicolumn{4}{|c|}{ Loét } & \multirow{3}{*}{$\begin{array}{l}\text { Thời } \\
\text { điểm } \\
\text { xuất } \\
\text { hiên } \\
\text { loét } \\
\text { (ngày } \\
\text { thứ) }\end{array}$} & \multicolumn{2}{|c|}{ Vị trí loét } & \multicolumn{2}{|c|}{ Giai đoạn loét } \\
\hline & \multicolumn{2}{|c|}{ không } & \multicolumn{2}{|c|}{ Có } & & & & & \\
\hline & $n$ & $\%$ & $n$ & $\%$ & & Lưỡi & Môi & I & II \\
\hline
\end{tabular}




\begin{tabular}{|c|c|c|c|c|c|c|c|c|c|c|}
\hline AnchorFast & $\begin{array}{c}\mathrm{n}= \\
30\end{array}$ & 26 & 86,67 & 4 & 13,33 & $\begin{array}{c}4,00 \pm \\
1,16\end{array}$ & $3(10 \%)$ & $1(3,33 \%)$ & $3(10 \%)$ & $\begin{array}{c}1(3,33 \% \\
)\end{array}$ \\
\hline Băng dính & $\begin{array}{c}\mathrm{n}= \\
30\end{array}$ & 20 & 66,67 & 10 & 33,33 & $\begin{array}{c}3,90 \pm \\
1,20\end{array}$ & $4(13,33 \%)$ & $6(20 \%)$ & $7(23,33 \%)$ & $3(10 \%)$ \\
\hline Tổng & $\begin{array}{c}\mathrm{n}= \\
60\end{array}$ & 46 & 76,67 & 14 & 23,33 & $\begin{array}{c}3,93 \pm \\
1,44\end{array}$ & $7(11,67 \%)$ & $7(11,67 \%)$ & $10(16,67 \%)$ & $\begin{array}{c}4(6,67 \% \\
)\end{array}$ \\
\hline
\end{tabular}

Nhận xét: Thời điểm xuất hiên loét của 2 phương pháp cố định đều xuất hiện vào ngày thứ 4 , trong đó tỷ lệ loét khi sử dụng băng dính cao gấp 2,5 lần sử dụng dụng cụ AnchorFast. Vị trí loét thường gặp nhất ở cả hai nhóm là môi và lưỡi với giai đoạn I chiếm ưu thế (10/ 14 bệnh nhân).

Bảng 3.5. Một số yêu tố liên quan đến loét áp lực của hai phương pháp cố định

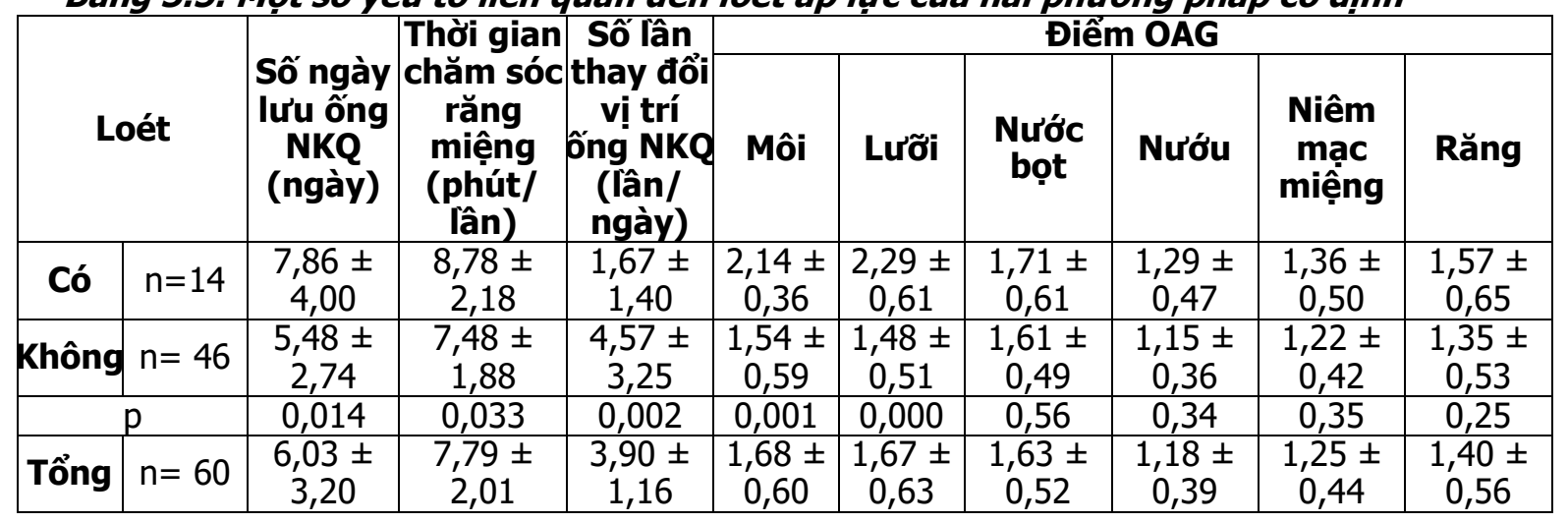

Nhận xét: Số ngày lưu ống NKQ, thời gian chăm sóc răng miệng, số lần thay đổi vị trí ống NKQ giữa 2 nhóm loét và không loét khác biệt có ý nghĩa thống kê với khoảng tin cậy $95 \%$ ( $<$ $0,05)$. Điểm OAG ở vị trí môi, lưỡi ở hai nhóm có loét và không loét khác biệt có ý nghĩa thống kê ở khoảng tin câyy $95 \%$ lần lượt là $p=0,001$ và $p$ $=0,000$. Tại vị trí nướu, nước bọt, niêm mạc miệng và răng, điểm $O A G$ giữa 2 nhóm loét và không loét có sự khác biệt không có ý nghĩa thống kê với khoảng tin cậy $95 \%(p>0,05)$

\section{BÀN LUÂN}

Có 60 người bênh nằm tai đơn vị hồi sức tích cực của khoa Cấp cứu \& hồi sức tích cực - Bệnh viện Đại học Y Hà Nội được đưa vào đối tượng nghiên cứu, với các bệnh lý cấp tính như sốc nhiễm khuẩn, nhiễm khuẩn huyết, xuất huyết não, nhồi máu não, viêm phổi, suy tim... trên các nền bệnh lý mạn tính đa dạng, trong đó nhóm có tiền sử mắc bệnh đái tháo đường chiếm cao nhất $(26,67 \%)$, đứng thứ 2 là nhóm có tiền sử mắc bệnh mach máu ngoại vi $(5 \%)$. Tỷ lệ này cũng tương đồng với nghiên của Hampson với kết quả lần lượt là $23,8 \%$ và $4,8 \%{ }^{1}$ Độ tuổi trung bình của đối tượng nghiên cứu là $64,9 \pm 18,13$; của nhóm AnchorFast là $66,50 \pm 18,86$; nhóm băng dính là $63,30 \pm 17,55$; độ tuối trung bình là tương đồng nhau giữa hai nhóm, sự khác biệt không có ý nghĩa thống kê ở khoảng tin cậy $95 \%$ $(p>0,05)$. Về thể trạng, BMI ở hai nhóm
AnchorFast và băng dính lần lượt là $22,39 \pm 4,33$ và 20,42 $\pm 3,09$, sự khác biệt có ý nghĩa thống kê ở khoảng tin cậy $95 \%(p<0,05)$.

Trong 60 bệnh nhân tham gia nghiên cứu được chia làm hai nhóm mỗi nhóm 30 bênh nhẩn, chúng tôi không ghi nhân bệnh nhân nào bị di lệch ống NKQ ở nhóm bệnh nhân sử dụng dụng cụ AnchorFast, trong khi đó có đến 7 bệnh nhân bị di lệch ống NKQ chiến 23,67\% với 6 bệnh nhân di lệch $1 \mathrm{~cm}$ và 1 bệnh nhân bị di lệch $2 \mathrm{~cm}$, vượt quá mức độ di lệch cho phép.

Theo báo cáo của Janna S. Landsperger, ống NKQ tuột 7 lần ở 6 bệnh nhân trong nhóm sử dụng AnchorFast chiếm 3,9\%. ${ }^{4}$ Trong nghiên cứu của chúng tôi ghi nhân 1 bệnh nhân bị tuột ống NKQ khi sử dụng cố định bằng băng dính. Với nhóm bệnh nhẩn sử dụng AnchorFast, chúng tôi chưa ghi nhận bệnh nhân nào bị tuột ống hoăcc rút ống ngoài ý muốn. Với kết quả thu nhận được, chúng tôi đánh giá rằng AnchorFast đạt hiệu quả cao trong việc cố định ống NKQ so với phương pháp băng dính.

Theo bảng 3.4, thời gian chăm sóc răng miệng bao gồm đánh răng, vệ sinh lưỡi và khoang miệng, vệ sinh ống NKQ của nhóm băng dính mất thời gian trung bình 9 phút, cao gấp 1,5 lần nhóm AnchorFast. Thời gian chăm sóc của nhóm băng dính dài hơn vì điều dưỡng sẽ phải thay băng dính mới cố định lại ống NKQ. Đây chính là bước chăm sóc mất thểm thời gian so với khi dùng AnchorFast và cũng là nguyên 
nhân thường gặp cho việc di lệch ống NKQ. Kết quả của nghiên cứu cũng tương đồng với báo cáo của Nguyễn Thi Châm tại bệnh viện $E$ năm 2018 với thời gian trung bình chăm sóc răng miệng của 2 nhóm băng dính và AnchorFast lần lượt là $8,48 \pm 0,30$ và $5,86 \pm 0,27 .{ }^{8}$ Bên cạnh hiệu quả về cố định chắc chắn, AnchorFast còn mang lại hiệu quả về thời gian và sự thuận tiên khi chăm sóc răng miệng. Cũng theo nghiên cứu của Nguyễn Thị Châm và các cộng sự, nhóm bênh nhân cố định AnchorFast dễ dàng và thuận tiện hơn trong chăm sóc răng miệng với tỷ lệ thuận tiện 95\%, nhóm băng dính tỷ lệ thuận tiện là $17,5 \%$, sự khác biệt có ý nghĩa thống kề với $p$ $<0,05$. $^{8}$ Điểu dương tại đơn vị hồi sức tích cực Bệnh viện đại học $Y$ Hà Nội cũng đều nhận xét rằng dụng cụ AnchorFast giúp thay đổi ống NKQ dễ dàng và linh hoạt, vì vậy công việc đánh răng và hút đờm hầu họng được thao tác dễ dàng và tiết kiệm thời gian.

Kết quả nghiên cứu của chúng tôi cũng chỉ ra rằng không có sư khác biệt về điểm đánh giá răng miệng tại 6 vị trí giữa 2 nhóm AnchorFast và băng dính, do hạn chế của nghiên cứu là số lần đánh giá điểm $\mathrm{OAG}$ chỉ được thực hiện một lần trong ngày và do nhiều nghiên cứu viên tham gia đánh giá nên kết quả chúng tôi thu nhận sẽ có sai số. Tuy nhiên, với 2 nhóm loét và không loét, chúng tôi ghi nhận được kết quả khác biệt với ý nghĩa thống kê tại 2 vị trí môi và lưỡi với $p$ lần lượt là 0,001 và 0,000 . Đây cũng là 2 vị trí loét ghi nhận được nhiều nhất trong nghiên cứu này. Một khuyến nghị được chúng tôi đưa ra là cân chăm sóc đặc biệt môi, lưỡi và số lần chăm sóc răng miệng cần thực hiện ít nhất 2 lần/ngày thay vì 1 lần/ ngày như hiện tại.

Tỳ lệ loét áp lực liên quan đến ống nội khí quản được cố định bằng dụng cụ chống cắn AnchorFast là $13,33 \%$ bằng $1 / 2,5$ tỷ lệ loét áp lực nhóm băng dính, song tỷ lệ này cao hơn rất nhiều lần so với các nghiên cứu trong và ngoài nước. Một nghiên cứu của ZaratkiewiczS (2012), tỉ lệ loét áp lực giảm xuống còn $0,2 \%$ ở những bệnh nhân được sử dụng AnchorFast. ${ }^{5}$ Cũng theo báo cáo của Janna S. Landsperger, loét môi có ở 4 bệnh nhân thuộc nhóm bênh nhân được cố định bằng AnchorFast, chỉ chiếm $2,4 \% .{ }^{4}$ Với nghiển cứu trong nước, tỷ lẹ loét áp lực của nghiên cứu này cao hơn gấp 3 lần so với nghiên cứu của Nguyễn Thị Châm và các cộng sự tại bệnh viện $\mathrm{E}$ năm $2018(3,7 \%){ }^{8}$ Điều này có thể giải thích do: cõ̃ mẫu nhỏ, thời gian tiến hành nghiên cứu ngắn, chưa thao tác đúng và sử dụng dụng cụ một cách hiệu quả.
Theo bảng 3.5, nhóm bệnh nhân bị loét có số lần thay đổi ống nội khí quản trong một ngày thấp hơn so với nhóm bệnh nhân không bị loét, sự khác biệt có ý nghĩa thống kê với khoảng tin cậy $95 \%(p<0,05)$. Một khuyến nghị có thể được đưa ra dựa trên kết quả của nghiên cứu là việc thay đổi vị trí ống nội khí quản thường xuyển góp phần giảm tỷ lệ loét áp lực liên quan đến dụng cụ cố định AnchorFast. Vì vậy, việc tuân thủ khuyến cáo của nhà sản xuất là thay đổi mỗi vị trí 2 giờ/ lần là thực sự cần thiết.

Cũng theo bảng 3.6, ở nhóm bệnh nhân bị loét, việc chăm sóc răng miệng sẽ mất nhiều thời gian hơn, sự khác biệt có ý nghĩa thống kê ở khoảng tin câyy $95 \%$ với $p<0,01$. Giai đoạn loét thường gặp trong nghiên cứu là giai đoạn I và II chiếm tỷ lệ lần lượt là $71 \%$ và $29 \%$. Với nhóm AnchorFast vị trí gặp loét nhiều nhất là lưỡi $75 \%$ gấp 3 lần vị trí môi (25\%). Từ những kết quả đó, chúng tôi nhận thấy vị trí lưỡi là vị trí chịu nhiều áp lực và dễ bị tổn thương nhất ở nhóm AnchorFast, cần quan tâm và chú ý chăm sóc nhiều hơn tại vị trí này.

\section{KẾT LUÂN}

Cố định ống NKQ bằng dụng cụ AnchorFast không có bệnh nhân nào bị di lệch ống NKQ, bị tuột ống và rút ống ngoài ý muốn. Trong đó ở nhóm sử dụng băng dính, tỷ lệ di lệch ống NKQ, tỷ lê tuột ống ngoài ý muốn là cao. Dụng cu cố định AnchorFast còn giúp giảm thời gian chăm sóc của điều dưỡng trong vấn đề vệ sinh răng miệng, thuận tiện trong hút đờm dãi và dễ dàng thay đổi vị trí ống NKQ phòng ngừa chấn thương áp lực. Tác dụng không mong muốn do dụng cụ AnchorFast ghi nhận được là loét áp lực thấp hơn nhiều so với nhóm dùng băng dính.

\section{TÀI LIÊUU THAM KHẢO}

1. Hampson, J., et al., Impact of the introduction of an endotracheal tube attachment device on the incidence and severity of oral pressure injuries in the intensive care unit: a retrospective observational study. BMC nursing, 2018. 17(1): p. 4.

2. Kaplow, R. and $M$. Bookbinder, A comparison of four endotracheal tube holders. Heart \& lung: the journal of critical care, 1994. 23(1): p. 59-66.

3. Gardner, A., et al., Best practice in stabilisation of oral endotracheal tubes: a systematic review. Aust Crit Care, 2005. 18(4): p. 158, 160-5.

4. Landsperger, J.S., et al., The effect of adhesive tape versus endotracheal tube fastener in critically ill adults: the endotracheal tube securement (ETTS) randomized controlled trial. Critical Care, 2019. 23(1): p. 161.

5. Zaratkiewicz, S., C. Teegardin, and J.D. Whitney, Retrospective review of the reduction of oral pressure ulcers in mechanically ventilated 
patients: a change in practice. Critical care nursing quarterly, 2012. 35(3): p. 247-254.

6. NPUAP, Pressure Injury Stages. 2016.

7. Huỳnh Văn Ân, M.T.T.B.D.v.c., Độ sâu thích hợp của ống nội khí quản qua đường miệng ở người
Việt Năm trưởng thành. 2006.

8. Nguyển Thị Châm, Đ.T.N., Pham Ngọc Thắng, Hoàng Thi Phương, Đánh giá hiêu quả ứng dung Anchor fast trong phòng loét tỳ đè liên quan đến nội khí quản. Tạp chí điều dưỡng Việt Nam, 2018.

\section{THỰC TRANG CẤP CỨU CHẤN THƯƠNG TRƯỚC VIỆN QUA CÁC TRƯỜNG HỢP CHẤN THƯƠ'NG SỌ NÃO NĂNG DO TAI NẠN GIAO THÔNG CẤP CỨU TẠI BỆNH VIỆN VIẸTT ĐỨC}

\section{TÓM TẮT.}

Đă̆t vấn đề: Cấp cứu trước viên (prehospital care), đặc biệt cấp cứu chấn thương quan trọng góp phần giảm nguy cơ biến chứng và tử vong, nhất là những trường hợp chấn thương so não (CTSN) do tai nan giao thông (TNGT). Chúng tồi thực hiện nghiên cứu đánh giá thực trạng cấp cứu trước viện để đề ra khuyến nghị. Đối tượng và phương pháp nghiên cứu: Tất cả bệnh nhẩn CTSN do TNGT được cấp cứu tại bệnh viện Việt Đức trong thời gian từ 31/12/2020 đến $31 / 3 / 2021$, không phân biệt giới, tuổi, địa phương và nghê, có hồ sơ đây đủ, bao gồm cả các ca năng vể và tử vong. Số liệu được xử lý phần mềm SPSS 20.0. Kêt quả: Tổng số 200 trường hợp cấp cứu CTSN nặng do TNGT, tuổi từ 21 - 60 chiếm 67,5\%, nam giới chiếm đa số 88,5\%; Thương tổn phối hợp: hàm mặt chiếm $44 \%$, chấn thương chi chiếm $23,5 \%$, chấn thương ngưo kín $22 \%$. Được cấp cứu ban đâuu tại cơ sở y tế chiếm tỷ lệ $96,5 \%$; Vận chuyển bằng xe cứu thương chiếm $98 \%$; nhân viển y tế đi cùng chiếm $97 \%$. Kỹ thuật đã làm: Ven truyền chiếm 97,5\%, NKQ và khai thông đường thở $85 \%$ và $84,5 \%$, nẹp cô $37,5 \%$. Xử trí tại viện: phẩu thuật cấp cứu chiếm $42 \%$. Kết quả xử lý: nặng xin về chiếm $24,5 \%$, tử vong chung chiếm $25 \%$. Kết luận và khuyến nghị: Các trường hợp cấp cứu CTSN do TNGT tại bệnh viện Việt Đức thời gian gân đây được tiếp cận cấp cứu trước viện, hầu hết bệnh nhân được xử trí ban đâuu tại cơ sở y tế và được vận chuyển xe cứu thương. Tuy nhiên tỷ lệ tử vong cò̀ cao, chúng tôi khuyến nghị cần tăng cường chất lượng cấp cứu trước viện nhất là với chấn thương sọ não.

Tư khoá: Chấn thương sọ não; Tai nạn thương tích, Chăm sóc trước viện.

\section{SUMMARY}

CURRENT TITUATION OF PREHOSPITAL CARE THROUGH THE BRAIN TRAUMATIC INJUFY DUE TO TRAFFIC ACCIDENT HAVE BEEN TREATED AT

\footnotetext{
1 Trường Đại học Thăng Long

${ }^{2}$ Bênh viện Hữu Nghi Viêt Đức

Chịu trách nhiệm chính: Đinh Văn Quỳnh

Email: quynhkbvd@gmail.com

Ngày nhận bài: 10.9.2021

Ngày phản biên khoa hoc: 28.10.2021

Ngày duyệt bài: 12.11.2021
}

\section{VIET DUC UNIVERSITY HOSPITAL}

Introductions: Prehospital care, especially trauma emergency is playing an important role to reduce morbidity and mortality, especially brain trauma related to traffic accident. We conducted a study through emergency cases at Viet Duc University Hospital aiming to assess the situation of prehospital care and to make recommendations. Materials and methods: All patients with brain trauma due to traffic accident have been treated at the hospital during the period from December 31, 2020 to March 31, 2021, regardless of gender, age, locality and profession, have complete records, including deaths. Data were processed using SPSS 20.0 software. Results: A total of 200 patients with severe brain trauma due to traffic accident were enrolled, age group from 21-60 years old accounted for $67.5 \%$, males in $88.5 \%$; Injuries associated were: maxillofacial trauma accounted for $44 \%$, limb injuries accounted for $23.5 \%$, chest trauma $22 \%$. The number of patients were provided the first aid at medical facilities accounted for $96.5 \%$; Transportation by ambulance accounted for 98\%; Medical staff accompanying patients while transporting accounted for $97 \%$. The procedures provided were IV accounted for $97.5 \%$, intubation and airway assessment with the rate of $85 \%$ and $84.5 \%$ respectively, collier for spine injury was in $37,5 \%$. The treatment on emergency at the hospital: $42 \%$ were operated on emergency. Treatment results: released to die accounted for $24.5 \%$, death in hospital $0.5 \%$, overall mortality was $25 \%$. Conclusions and recommendations: The study showed that brain trauma due to traffic accident at Viet Duc University Hospital, having access to prehospital care have improved, most of the patients were initially provided the first aid at the medical facilities and transported by ambulances. However, the mortality rate is still related high, we recommend strengthening the prehospital care especially with traumatic brain injury.

Keywords; Traumatic brain injury; Injury, Prehospital care.

\section{I. ĐẶT VẤN ĐỀ}

Tai nạn thương tích (TNTT) vẫn là vấn đề toàn cầu, nguyên nhân chủ yếu của các trường hợp bị TNTT và tử vong là tai nạn giao thông (TNGT), đặc biệt là tai nạn giao thông đường bộ (TNGTĐB). Cứ mỗi 6 giây có một trường hợp tử 